\title{
Production of biologically and toxicologically safe semi-solid and wet anatomic preparations
}

\author{
$S$. Vorobievskaya*, $M$. Stacenko, $V$. Dronov, and $I$. Kulachenko \\ Belgorod State Agricultural University named after V. Gorin, 308503, 1, Vavilova, st., vill. Mayskiy, \\ Belgorod region, Russian Federation
}

\begin{abstract}
One of the main goals of applied morphology is to make the teaching of normal anatomy visual. Natural preparations of organs and body parts of an animal should be demonstrative enough and retain their shape and appearance for a long time. Compared to others, the method that we have developed for the manufacture of anatomical preparations has significant advantages, and in such a quality that makes it possible to study the object not only visually, but also manually. At the same time, soft anatomical preparations made in this way are biologically and toxicically safe. Preservation of organs and tissues of animal corpses is a necessary part of the work of anatomists and pathologists with the obligatory use of these preparations in the educational process, including for independent work of students. The method that we have optimized for the manufacture of wet pathological specimens, which have high visibility, close to the natural color and shape of eviscerated organs and tissues, while being stored longer.
\end{abstract}

\section{Introduction}

The faculty has collected and manufactured enough material on normal anatomy. These are animal skeletons, individual bones, wet preparations.

All these tutorials help to understand the structural features of the body. In our work, we often encounter the fact that the study of some preparations, which is often very difficult, especially if the preparation is hermetically sealed in a museum vessel.

The purpose of our work is to develop methods for the manufacture of soft and moist pathological anatomical preparations that have a high visibility, close to the natural color and shape of natural organs and tissues, which are of great interest to their study, not only visually, but, which is very important and manual. They are more informative and have a long service life and, importantly, the least expensive $[10,11]$.

Compared to previous methods, anatomical preparations made in this way have significant advantages.

Therefore, we have developed a method for the manufacture of soft postmortem preparations (organs and tissues), in such a quality that makes it possible to study the object

\footnotetext{
${ }^{*}$ Corresponding author: vorobievsckaya@yandex.ru
} 
not only visually, but also manually. At the same time, soft anatomical preparations made in this way are biologically and toxicically safe [6].

There have been recorded methods of making similar anatomical preparations that were used earlier, but they all have significant drawbacks. In one case, expensive equipment and materials are required for their manufacture, in another, an unsatisfactory end result takes place $[2,3,4,7,8,9]$.

The first of these is the plastination method.

Standard Plastination Technique

During the plastination process, tissue water and part of tissue fat are replaced by a polymerizing resin (BIODAR). Polymerization occurs inside the sample, ensuring its more complete preservation:

- fixation;

- dehydration;

- forced impregnation;

- preservation.

Fixation is performed using conventional fixation technique with formaldehyde.

Dehydration of samples necessarily precedes polymer impregnation. The available method is the cold displacement method. The sample is placed in acetone at $-25{ }^{\circ} \mathrm{C}$ for several weeks. Acetone is replaced until its water content is less than $1 \%$.

The forced impregnation process is the central and most important stage of plastination. After saturation of the sample with acetone, it is immersed in a polymer solution (BIODAR-polymer).

Volatile acetone is removed from the sample by a vacuum pump. This creates a pressure differential that causes the polymer solution to penetrate into the sample.

Impregnation must be performed slowly to allow the polymer solution to penetrate where the acetone enters the gas phase and is removed (sucked out or boiled away).

Impregnation takes 4 to 14 days, depending on sample size, tissue density and polymer solution viscosity. During this period, the vacuum should gradually increase (from a pressure of about $200 \mathrm{~mm} \mathrm{Hg}$ to $5 \mathrm{~mm} \mathrm{Hg}$ ), when the evaporation of the medium practically stops. After impregnation, the sample is removed from the polymer solution and preserved.

Preservation of the impregnated sample is carried out at a temperature from room temperature to $+50-\mathrm{C}$, depending on the nature of the polymer used. A special method is gas preservation, when the impregnated sample is in contact with a gas medium to complete the polymerization.

For plastination, special equipment is required, which consists of a conventional lowtemperature freezer, a vacuum chamber with a window for visual inspection and a plate for plastination, as well as a vacuum pump, pressure gauge, vacuum tubes, bypass valve and acetone meter. Consumables: acetone, BIODAR 3.10 (5 kg), BIODAR hardener 3.3 (100 g) and BIODAR gas preservative $(1 \mathrm{~kg})$.

Plastination is a modern technology for processing and preserving cadaveric material. Its purpose is to replace the main components of the body (fluid and fat) with a neutral polymer. However, the implementation of this method requires expensive equipment and materials. In the manufacture of pathological preparations in this way, formalin and acetone are used, they are extremely toxic. The production time is long, from one year to several years. In this case, the drug needs to be painted, since it becomes discolored when treated with acetone, and this is additional material costs. Anatomical preparations made in this way cost tens and hundreds of thousands of rubles.

The second method, which is used for the manufacture of this kind of pathological preparations, is a method of making anatomical preparations using a polymer mixture developed by V. A. Zabrodin et al. a method involving the following stages of work: 
- flushing an organ through the artery feeding it with a solution of heparin 1: 1000 in a volume of 1: 5 - 10 in relation to the volume of the organ.

- pouring through the same vessel of the organ 10-12\% formalin followed by fixation in it for 7-10 days.

- preparation of the organ (making an anatomical specimen).

- drying the specimen by blotting or under a stream of warm air (avoid darkening of the organ).

- dehydration and soaking of the drug in a mixture of $96 \%$ alcohol and glycerin in a 1 : 1 ratio for 3-5 days.

- air drying (1-2 hours).

- immersion of the drug in a polymer mixture for a period of 5-10 days (depending on the volume and density of the organ).

- removing the drug from the mixture, shaping it and installing it.

- drying and airing the drug for 2 days. After that the preparation is ready for use.

The polymer mixture is prepared by dissolving polyurethane foam (foam) in xylene in a ratio of 1: 2 until the air bubbles completely disappear and possible suspensions settle (5-10 minutes - depending on the degree of crushing of the foam) .

This polymer mixture retains the color of histological dyes that can be used for staining the preparation.

During long-term (2-3 weeks) storage of the drug in open form, its tissues require restoration of their original volume, which is achieved by immersing the drug for 1-2 days in a polymer mixture, which can also be used for storage. $\{\{1\}\}$ But this method has significant drawbacks. In the manufacture of pathological preparations in this way, their color is not natural, and they are very hard to the touch, which removes them from naturalness and often have to be restored.

The third method that we used in the manufacture of soft pathological anatomical preparations is a method that consists of 3 phases.

The first 2 phases as prescribed by Melnikov-Razvedenkov.

The first phase - fixing the material in saline formalin, consists in immersing the drug in the following solution:

- formalin - $100 \mathrm{ml}$;

- potassium acetate (sodium) - $30 \mathrm{~g}$;

- chloride potassium - $5 \mathrm{~g}$;

- boiled water $-1000 \mathrm{ml}$.

The volume of the liquid should be 5-8 times the volume of the drug. The drug is kept in this liquid until it takes on a dirty rusty color.

The preparation is kept in the fixing liquid until the tissues are evenly compacted. This takes from 1 to 15 days, depending on the structure and size of the organ.

It is not recommended to overexpose the drug in the fixing liquid, since hemoglobin with prolonged exposure to formalin turns into persistent acidic hematin, which cannot be reduced by alcohol. Only fresh organs should be taken from the corpse, without washing them with water or wiping them. For faster penetration of formalin into tissues, it is recommended to make deep cuts on the back of the preparation.

The second phase - after the preparation is fixed in the first solution, it is removed, allowed to drain, dried with a towel and immersed in 95\% ethyl alcohol. Color recovery occurs in 1-2 hours for small and flat organs and 3-6 hours for large parenchymal organs. Staying the drug in alcohol for more than 12 hours is unacceptable, as it becomes discolored and wrinkled.

In the third phase, we took the DI Vyvodtsev's solution as a basis:

- glycerin - $1700 \mathrm{ml}$ 
- water - $1000 \mathrm{ml}$;

- thymol - $5 \mathrm{~g}$.

Similar methods of making wet pathological specimens, which we used earlier and on the basis of which we developed a new affordable and cheap method, are:

Methods of making preparations in liquids without preserving the natural color.

The most common fixative is formalin. Usually, for the first few days, the organ is fixed in a 5\% formalin solution with 2-3 times its change, after which it is transferred to a $10 \%$ solution. For even fixation of the organ, it can be suspended in a solution or straightened on sticks or struts. To avoid floating up very light organs, they should be fixed with a small weight or by attaching the preparation to a glass plate. During a break in work, the organ should be stored in a preservative liquid or wrapped in a cloth soaked in a suitable solution and covered with oilcloth.

A serious disadvantage of this method of making wet pathological preparations is that formalin is a very toxic substance that has a pronounced carcinogenic property. Instead of formalin for fixing organs, we also used other preservatives.

The most accessible formulations of fixing fluids:

Modified P.A. Minakov:

1. formalin - $100 \mathrm{ml}$;

2. ethyl alcohol - $100 \mathrm{ml}$;

3. water $-800 \mathrm{ml}$.

A.I. Kazantsev:

1. hot saturated solution;

2. of sodium chloride - $1000 \mathrm{ml}$;

3. carbolic acid - $30 \mathrm{~g}$.

Solution recommended by the Department of Topographic Anatomy and Operative Surgery I MMI named after I.M. Sechenov:

1. glycerin - $1000 \mathrm{ml}$

$2.10 \%$ formalin solution $-200 \mathrm{ml}$;

$3.5 \%$ sodium chloride solution $-1000 \mathrm{ml}$;

$4.96 \%$ alcohol - $500 \mathrm{ml}$;

5. carbolic acid - $500 \mathrm{~g}$.

(Before pouring, the solution is heated to $40-45^{\circ} \mathrm{C}$.)

A significant disadvantage of these methods for the manufacture of wet pathoanatomical preparations is that the natural color of organs and tissues is not preserved. Under the influence of alcohol, acids, formalin, they become discolored.

Methods of making preparations in liquids with preservation of their natural color, according to Melnikov-Razvedenkov.

The technique consists of three phases:

1 - the phase of fixing the material in salt formalin;

2 - the phase of color restoration in strong alcohols;

3 - the phase of preserving the drug in glycerol-acetic solution solution.

The fixation phase consists in immersing the drug in the following solution:

1. formalin - $100 \mathrm{ml}$;

2.potassium acetate (sodium) - $30 \mathrm{~g}$;

3. potassium chloride - $5 \mathrm{~g}$;

4. boiled water $-1000 \mathrm{ml}$.

The volume of the liquid should be 5 - 8 times the volume of the drug. The drug is kept in this liquid until it takes on a dirty rusty color.

This takes from 1 to 15 days, depending on the structure and size of the organ. So, the necessary fixation of the stomach, intestines, bladder is achieved in one day; heart - in almost 3-4 days; brain, liver - after 15 days. It is not recommended to allow overexposure 
of the drug in the fixing liquid, since hemoglobin with prolonged exposure to formalin turns into persistent acidic hematin, which cannot be restored with alcohol. Only fresh organs should be taken from the corpse, without washing them with water or wiping them.It is forbidden to remove blood, because the intensity of the color depends on its quantity. For faster penetration of formalin into the tissues, it is recommended to make deep incisions along the back of the preparation.

Upon completion of the fixation of the preparation in the first solution, it is removed, allowed to drain, dried with a towel and immersed in 80-95\% alcohol (denatured alcohol not suitable) ... Color recovery occurs in 1-2 hours for small and flat organs and 3-6 hours for large parenchymal organs. Staying the drug in alcohol for more than 12 hours is unacceptable, as it becomes discolored and wrinkled.

When the color of the drug is restored, it is transferred to a saline solution of glycerin, in which it can be stored indefinitely. The composition of this solution:

1. pure glycerin - $600 \mathrm{ml}$;

2. potassium acetate $-400 \mathrm{~g}$;

3. distilled water - $1000 \mathrm{ml}$ (water can be boiled).

Close the preparation in the bank cannot immediately, since sometimes the liquid turns brown and must be replaced. To prevent the appearance of mold, it is recommended to put a few crystals of thymol in the jar.

Our methods of making semi-solid and wet anatomical preparations involves the use of ingredients that are available at the Department of Morphology and Physiology, taking into account their properties.

\section{Methods}

The most optimal way of making soft anatomical preparations, during the experiment, for us turned out to be - the method, which consists from three phases.

For this, organs and tissues were used only that were extracted from the corpse of an animal. In this case, the blood was not removed. The color intensity of the finished soft pathoanatomical preparation depends on its quantity [1].

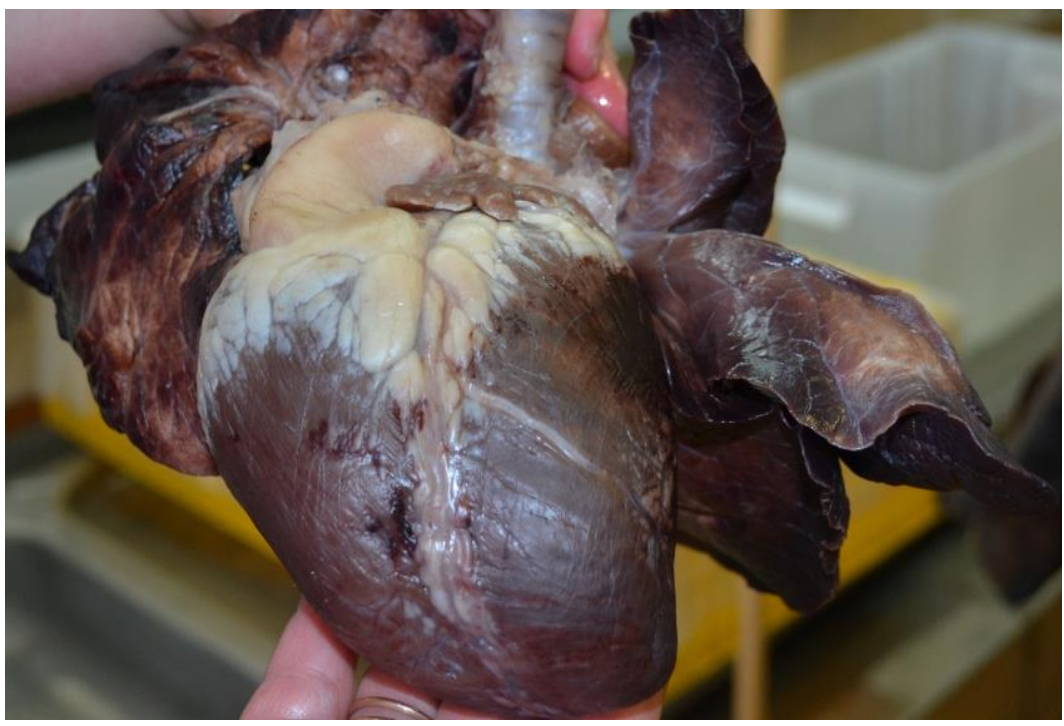

Fig. 1. Heart (semi-solid preparation). 
In the manufacture of soft pathological anatomical preparations, it is necessary, before fixation, to an organ, especially a hollow, or tissue to give a demonstration shape using cotton wool, gauze, wooden spacers.

The first phase - fixation of an organ or tissue in a solution containing:

- formalin - $60 \mathrm{~g}$;

- sodium acetate - $100 \mathrm{~g}$;

- potassium chloride - $10 \mathrm{~g}$;

- distilled water - $1000 \mathrm{~g}$.

The volume of the liquid should be 3 times the volume of the fixed preparation. In this liquid, the drug is kept until the tissues are uniformly thickened and the blood is no longer extracted into the solution.

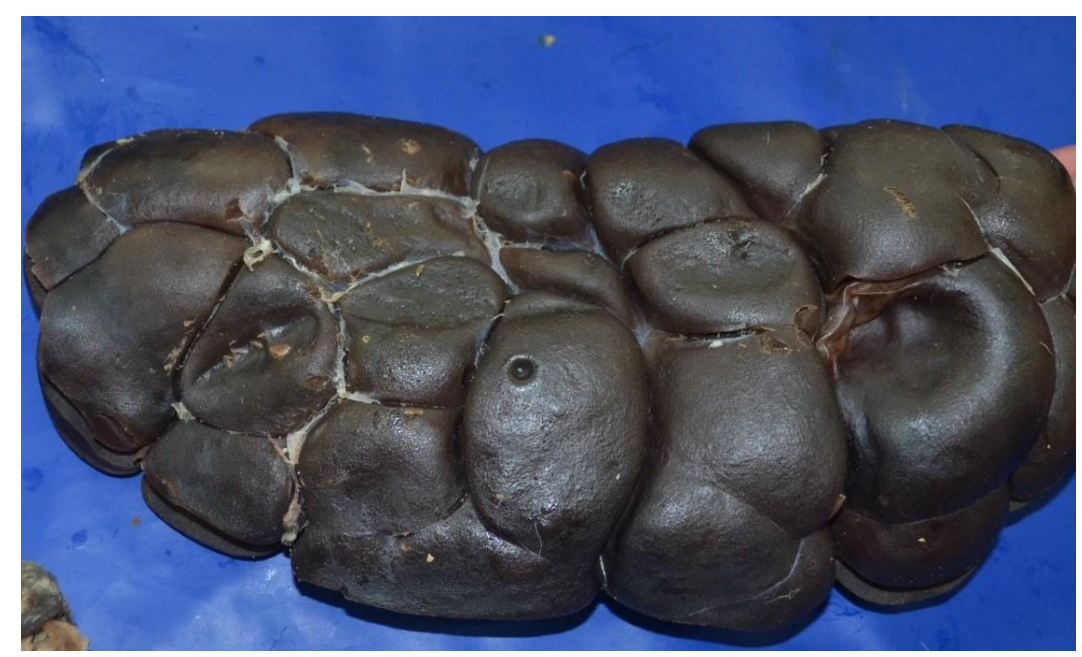

Fig. 2. Bovine kidney (semi-solid preparation).

The holding time ranges from several hours to 1 month. It depends on the size, density, structure of the organ. A prerequisite is that the air temperature does not exceed +5 and the exposure is long enough with the replacement of the solution with a new one every 5 days. The room in which the drug is fixed should be dark, or the containers should not be transparent.

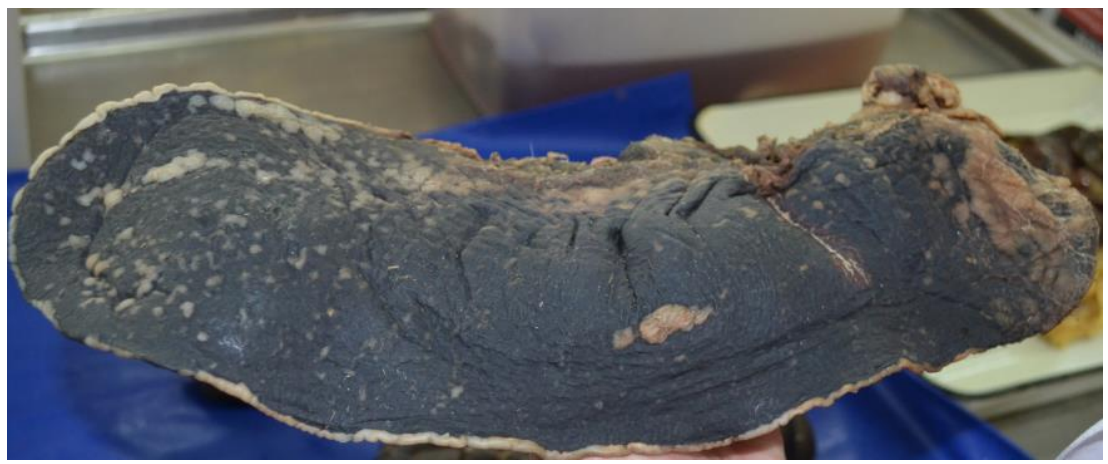

Fig. 3. Bovine spleen (semi-solid preparation). 
It is not recommended to overexpose the drug in the fixing liquid, since hemoglobin with prolonged exposure to formalin turns into persistent acidic hematin, and in this case, recovery with alcohol is not possible.

Upon completion of the fixation, the drug was removed from the first solution and allowed to drain completely. Then the fixed material was transferred into $95 \%$ ethyl alcohol.

Second phase - color restoration in 95\% ethyl alcohol.

Exposure in $95 \%$ ethyl alcohol takes from several minutes to 3 hours, depending on the size and density of the organ and tissue. It is undesirable to overexpose the drug in alcohol, as it becomes discolored [9].

After color recovery, the organs were transferred to containers with a preservative solution.

Third phase - immersion in a solution containing:

- glycerin - $3800 \mathrm{~g}$

- water $-1000 \mathrm{~g}$

- sodium acetate - $30 \mathrm{~g}$

- thymol - $10 \mathrm{~g}$

The solution must completely cover the organs and tissues. The exposition is from 2 to 4 months. This solution can be reused.

The method of making wet anatomical preparations includes three phases of preparation.

In the manufacture of pathological preparations, it is necessary to give a demonstration shape to an organ, especially a hollow one, or tissue even before fixation with the help of cotton wool, gauze, with which the cavities are filled.

First phase - fixation of an organ or tissue in a solution containing:

- formalin - $35 \mathrm{~g}$;

- sodium acetate - $80 \mathrm{~g}$;

- potassium chloride - $10 \mathrm{~g}$;

- distilled water $-1000 \mathrm{~g}$.

The volume of the liquid should be 4 times the volume of the fixed preparation. In this liquid, the drug is kept until the tissues are uniformly thickened and the blood is no longer extracted into the solution.

The holding time ranges from several hours to 2 weeks. It depends on the size, density, structure of the organ.

It is categorically not recommended to overexpose the drug in the fixing liquid, since hemoglobin with prolonged exposure to formalin turns into persistent acidic hematin, and in this case recovery with alcohol is not possible.

It should be noted that a decrease in the amount of formalin during fixation (in the first phase) of $30 \mathrm{~g}$ per $1000 \mathrm{~g}$ of water made it possible to keep the color of the organ close to natural. A prerequisite is that the air temperature does not exceed +5 and the exposure is long enough with the replacement of the solution with a new one every 5 days. The room in which the drug is fixed should be dark, or the containers should not be transparent. Upon completion of fixation, the drug is removed from the first solution, allowed to drain completely.

In the second phase - (color recovery), the fixed material is transferred into $95 \%$ ethanol.The exposure in it ranges from several minutes to 1 hour, depending on the size, density of the organ or tissue. It is undesirable to overexpose the drug in alcohol, as its discoloration occurs.

After the color is restored, the organs are transferred to containers with a preservative solution. 
The third phase is to immerse the drug in a non-demonstration container and keep it in a preservative solution for several days (in case further blood is extracted into the solution), and then transfer the drug to an anatomical vessel, fix it and fill it with a new preservative solution consisting of:

- glycerin - $880 \mathrm{~g}$;

- sodium acetate - $500 \mathrm{~g}$;

- water - $1000 \mathrm{~g}$;

- thymol - $10 \mathrm{~g}$.

Conditions for preparation of the preservative solution: dissolve sodium acetate in water and bring to a boil, then add glycerin there and let the solution boil well. After the solution has cooled, add thymol to it and pour the preparation into a demonstration vessel, which should be hermetically sealed with silicone sealant. The solution must completely cover the organs and tissues.

\section{Results}

The methods of making the preparations that we have developed have made it possible to obtain anatomical and pathological preparations with high clarity, close to the natural color and shape of natural organs and tissues.

Compared with the methods described in the literature and which we used earlier, they have a number of significant advantages. They consist in the fact that in the manufacture of these drugs, a very small amount of formalin is used, which, as you know, is a very toxic substance and tends to accumulate in the human body, which is extremely harmful to the health of not only students, teachers, but also visitors of pathological anatomical museums.

These textbooks and exhibits are devoid of unpleasant odor, which makes them more comfortable to study.

Compared to preparations made traditionally, ours are of great interest in their study, since this can be done not only visually, but, which is very important and manual. They can be freely picked up, they have a similar density to natural organs and tissues and, as a result, are more informative and have a long service life. The preparations made according to the methods we have optimized are already more than 10 years old and for the most part they have their original appearance.

You don't need to have expensive equipment and reagents to make them.

\section{Discussion}

As a result of the manufacture of anatomical preparations by the method of plastination (using polymers), in comparison with preparations made according to our method, they are very hard to the touch and require coloring, and glycerin preparations made (according to Vyvodtsev) in the open air quickly dry out, lose their elasticity and color.

We were not completely satisfied with either of these two methods.

Wet preparations are also in demand, which are very demonstrative, they are stored for a long time in hermetically sealed containers. But their disadvantage is that the proposed fixing and preserving solutions, despite the fact that they provide long-term storage of drugs, often discolor organs and tissues, if not immediately, then over time.

Therefore, we have developed a method for the manufacture of wet anatomical specimens that retain their natural color and are less toxic. The main prototype of our method is a method of making wet preparations according to 
Melnikov - Razvedenkov, but its disadvantage is that not all organs and tissues manage to retain their color. According to our observations, when stored in a preservative solution, organs and tissues quickly fade and eventually discolor. This is because the fixing solution contains $100 \mathrm{ml}$ of formalin per 1 liter of water, and our formulation uses $35 \mathrm{ml}$ of formalin per 1 liter of water.

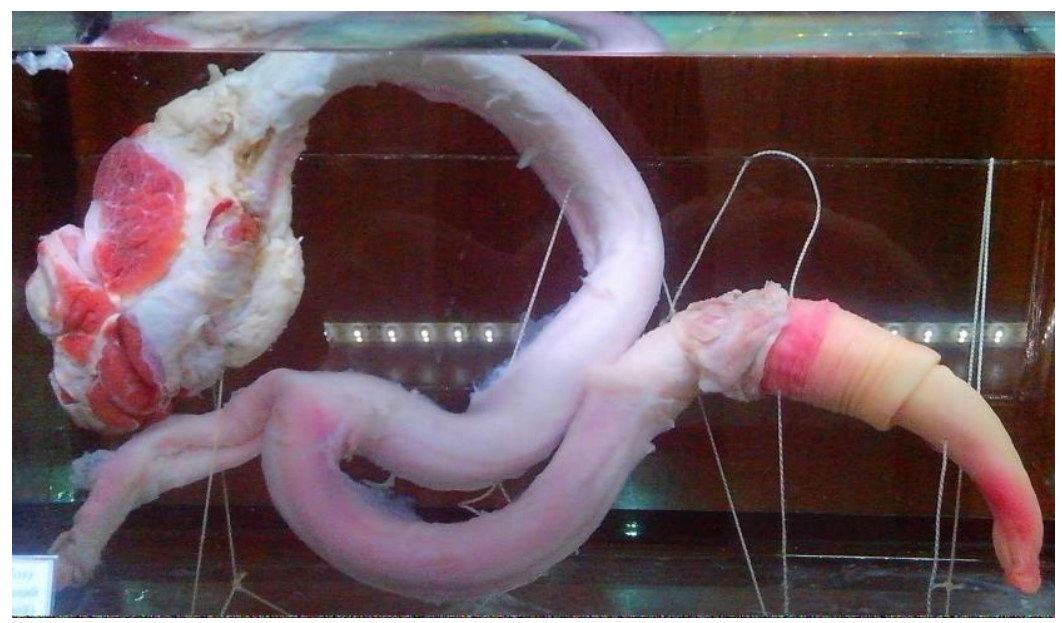

Fig. 4. Cattle penis (wet preparation).

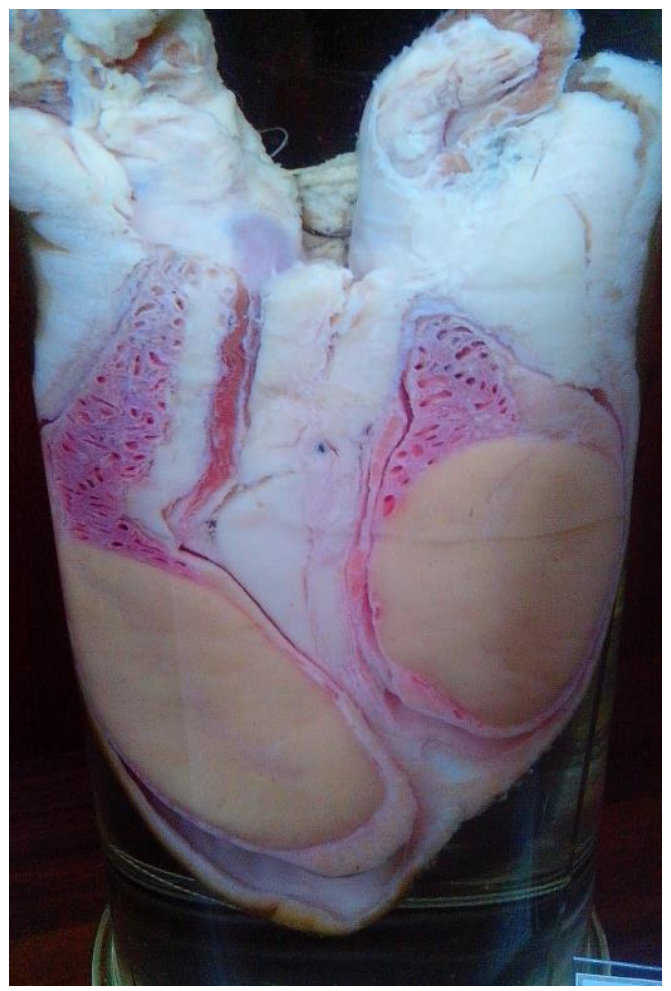

Fig. 5. Testes of cattle (wet preparation). 


\section{Conclusion}

Medicine, including veterinary medicine, is unthinkable without fundamental knowledge in the field of human and animal anatomy. This science is difficult to study and often, especially at the initial stage, this process is complicated by the presence of unpleasant odors, which is associated with the development of post-mortem changes in biological objects used by morphologists.

The biological, toxic safety, mobility and aesthetics of these preparations make soft anatomical preparations easy to use, not only for the educational process, but also involves their participation in educational expositions for an untrained audience.

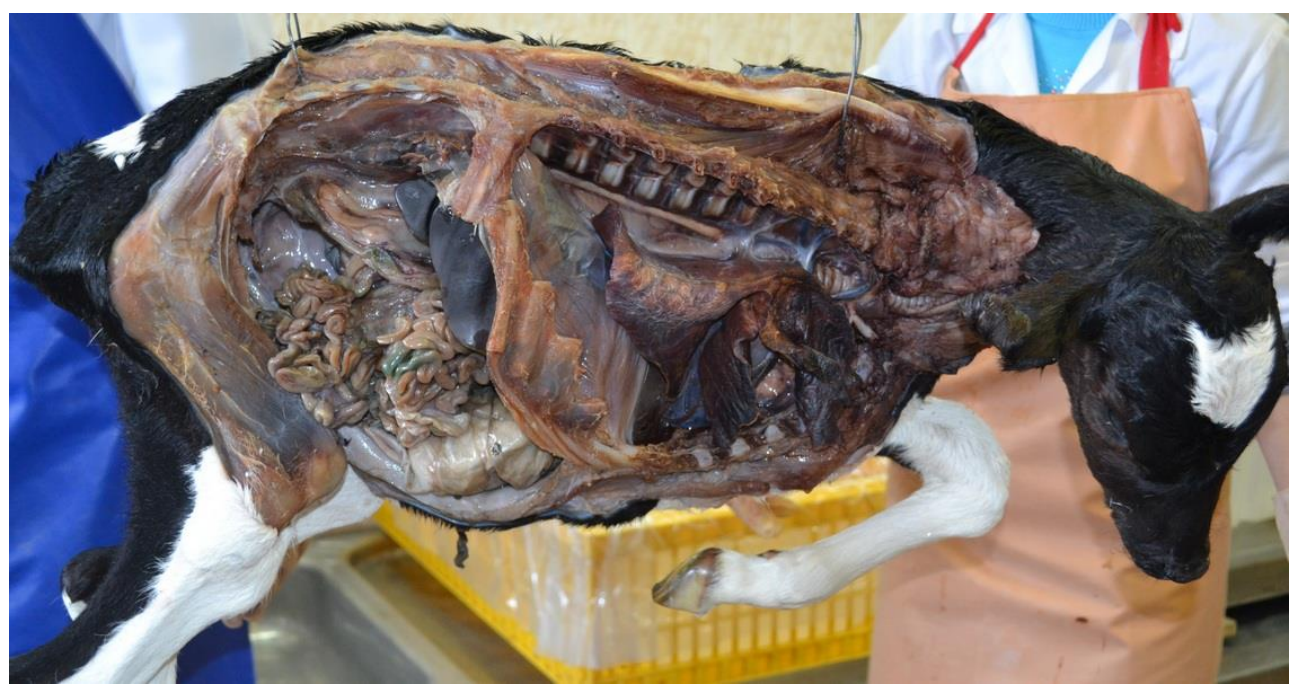

Fig. 6. Neonatal calf (semi-solid preparation).

1. They are non-toxic, odorless and have no harmful effects on the human body.

2. They have high visibility, are close to the natural color and shape of natural organs and tissues.

3. It is important that the quality of the finished anatomical specimens makes it possible to study them not only visually, but also manually.

4. Stored outdoors, without the use of hermetically sealed containers.

5. The shelf life of such drugs is not limited.

6. If necessary, after a few years, they can be renewed by soaking for one week in the preservative solution used in the third phase.

7. Our manufacturing methods are the least expensive, while using those substances that are not scarce and are available at the department in sufficient quantities.

Biological, toxic safety, and aesthetics of these drugs makes them easy to use, not only in the educational process, but also involves participation in museum pathological exhibitions of an educational nature, even for an unprepared audience.

\section{References}

1. S.V. Vorobievskaya, Materials of the XX International Scientific and Production Conference (2016)

2. V.S. Pikalyuk, G.A. Moroz, S.A. Kutia, Methodical manual for the production of anatomical preparations (2004) 
3. L.E. Kuznetsov, V.V. Khokhlov, S.P. Fadeev, V.B. Shigeev, Embalming and Restoring Corpses: A Manual (1999)

4. B. Belkin, A. Zharov, V. Prudnikov, Pathomorphological diagnostics of animal diseases Atlas-album (Moscow, "Aquarium", 2013)

5. D.A. Pomeshchikova, M.S. Nuralieva, S.V. Vorobievskaya, I.V. Kulachenko, Materials of the international student scientific conference (2015)

6. M.D. Statsenko, S.V. Vorobievskaya, Materials of the international student scientific conference (2017)

7. K.T. Onwuama, S.O. Salami, O. Ali, J.O. Nzalak, Int. J. Morphol., 30, 2 (2012)

8. O.J. Ezugwori, Journal of Experimental and Clinical Anatomy (2001)

9. R.G. Mayor, Embalming: History, Theory and Practice (McGraw - Hill, Appleton and Lange, 2000)

10. L.G. Frederick, K.G. Strub, The principles and practice of embalming (Dallas, 1989) 